\title{
Segmental Limb Volume Change as a Predictor of the Onset of Lymphedema in Women With Early Breast Cancer
}

\author{
Nicole L. Stout, PT, MPT, CLT-LANA, Lucinda A. Pfalzer, PT, MA, PhD, FACSM, FAPTA, \\ Ellen Levy, PT, OCS, Charles McGarvey, PT, DPT, MS, FAPTA, \\ Barbara Springer, PT, PhD, OCS, SCS, Lynn H. Gerber, MD, Peter Soballe, MD
}

Objective: To demonstrate that segmental changes along the upper extremity occur before the onset of breast cancer-related lymphedema (BCRL). These changes may be subclinical in nature and may be predictive of the onset of chronic lymphedema.

Design: A retrospective subset analysis of a larger prospective cohort trial.

Patient Cohort: A total of 196 patients provided consent and were enrolled in the prospective study. Subclinical lymphedema developed in 46 of these patients. Limb volume data were available for 45 of these 46 patients from visits before the onset of lymphedema and were used in this analysis. We compared this group with an age-matched control group without BCRL from the same cohort $(n=45)$.

Setting: Military hospital outpatient breast care center.

Methods: Women were enrolled and assessed preoperatively. Baseline measures of limb volume were obtained with the use of optoelectronic perometry, and reassessment was conducted at $1,3,6,9$, and 12 months postoperatively. BCRL was identified in 46 of 196 women at an average of 6.9 months postoperatively. A retrospective analysis was conducted in which we examined volume changes over four $10-\mathrm{cm}$ segments of the limb at the visits before the onset of BCRL. By using repeated-measures multivariate analysis of variance, we compared segmental volumes between groups at preoperative baseline, time of diagnosis of BCRL, and time of follow-up after early intervention. Linear regression analysis was performed to determine the strength of the relationship between total limb volume change with segmental volumes at the time of diagnosis of BCRL.

Main Outcome Measurements: We hypothesized that segmental volume changes occur and can be measured in the limb before the onset of lymphedema.

Results: At arm segments $10-20 \mathrm{~cm}(P=.044)$ and $20-30 \mathrm{~cm}(P<.001)$, a significant volume increase was noted before the diagnosis of subclinical BCRL. Segmental volume changes correlated to the total limb volume (TLV) change. At segments $20-30 \mathrm{~cm}$, the coefficient of determination was $r^{2}=0.952$, and at $10-20 \mathrm{~cm}$ it was $r^{2}=0.845$, suggesting that these segments predicted TLV changes.

Conclusion: Serial interval assessment of limb volume segments may be an important clinical tool to detect early-onset lymphedema before TLV changes.

PM R 2011;3:1098-1105

\section{INTRODUCTION}

Breast cancer-related lymphedema (BCRL) is defined as an abnormal accumulation of fluid in the soft tissues of the upper limb [1]. Clinically apparent BCRL is a visible and often palpable swelling. This condition is a uniquely progressive and chronic late effect of breast cancer treatment that contributes to loss of limb function and disability [2-4]. Prospective interval limb volume assessment for the signs and symptoms of BCRL is widely prescribed [5-7]. This approach contributes to early diagnosis and may prevent BCRL $[6,8,9]$.

An optimal monitoring strategy involves a preoperative clinical assessment followed by ongoing prospective surveillance to measure limb volume and subjective reports of arm symptoms [6,8-11].
N.L.S. National Naval Medical Center, 8901 Wisconsin Avenue, Breast Care Center Bldg. 19, 3rd floor, Bethesda, MD 208895600. Address correspondence to N.L.S.; e-mail: Nicole.stout@med.navy.mil Disclosure: nothing to disclose

L.A.P. University of Michigan-Flint, Flint, MI Disclosure: 8B, intramural funding at the $\mathrm{NIH}$, CRC, Rehabilitation Medicine Department, PT Section and the Breast Care Center at the National Naval Medical Center; 2, Breast Care Center at the National Naval Medical Center, $\mathrm{NIH}$

E.L. National Institutes of Health, Bethesda, MD

Disclosure: $8 \mathrm{~A}$, intramural program of the $\mathrm{NIH}$

C.M. National Institutes of Health, Bethesda, MD, and CLM Consulting Rockville, MD Disclosure: nothing to disclose

B.S. Office of the Surgeon General, Falls Church, VA

Disclosure: nothing to disclose

L.H.G. National Institutes of Health, Bethesda, MD, and George Mason University, Fairfax, VA Disclosure: 8B

P.S. National Naval Medical Center, Breast Care Center, Bethesda, MD, and Naval Medical Center San Diego, CA

Disclosure: nothing to disclose

Peer reviewers and all others who control content have no relevant financial relationships to disclose.

This research was Institutional Review Board approved and funded by the National Naval Medical Center, Bethesda, MD (protocol NNMC\# 2001-052) and the National Institutes of Health, Mark O. Hatfield Clinical Research Center, Rehabilitation Medicine Department, Physical Therapy Section, Bethesda MD (protocol NIH\# 02-CC-0044). The views expressed in this article are those of the author(s) and do not necessarily reflect the official policy or position of the Department of the Navy, Department of the Army, Department of Defense, or the U.S. Government.

Submitted for publication March 31, 2011; accepted July 25, 2011 
This method enables the quantification of limb volume variability preoperatively, before lymphatic disruption occurs; with prospective monitoring, the clinician can detect the earliest onset of limb volume changes, which may be subclinical [6]. Several valid measurement tools exist and can be methodologically standardized to accurately assess limb volume [12-16].

Historically, total limb volume (TLV) change has been the objective measure used to identify and quantify BCRL. However, limb swelling related to BCRL often does not occur uniformly throughout the extremity. Anatomical differences in lymphatic pathways of the limb have been identified radiographically $[17,18]$ and demonstrate segmental variance in drainage from the deeper subfascial limb compartment, from the forearm, and from the hand [19-22]. The clinical translation of this work leads us to hypothesize that the onset of limb swelling might also follow a segmental distribution and that perhaps TLV may not be sensitive enough in some instances to detect the early onset of BCRL.

The purpose of this study is to examine the relevance of segmental volume changes in the upper limb before the onset of BCRL. We hypothesized that measuring limb volume at $10-\mathrm{cm}$ segments of the arm would detect early swelling and may be predictive of the onset of BCRL. We also sought to determine whether these segmental volume measures would identify changes over time with early treatment intervention.

\section{METHODS}

A total of 196 women with early-stage breast cancer provided informed consent in accordance with the Declaration of Helsinki and were enrolled in an observational prospective morbidity study approved by the Institutional Review Board of the National Naval Medical Center. Patients were excluded from enrollment if they had bilateral breast cancer or a history of upper extremity or neck trauma or surgery, or if they were male. Subjects were evaluated by a physical therapist for an initial (baseline) examination and at 1, 3, 6, 9, and 12 months postoperatively. Bilateral upper extremity range of motion and strength were tested with the subjects seated. Volume and girth measurements for both upper limbs were obtained in a standard position as described by Stout Gergich et al [6] with the use of an optoelectronic volumeter containing a framed infrared scanning system, the Perometer (Pero-System Messgerate; Am Tescher Busch, Wuppertal, Germany). This instrument was designed specifically to measure girth $(\mathrm{cm})$ and volume $(\mathrm{mL})$ of the upper or lower extremities and has been validated for use in a clinical environment [23]. Tests and measures were repeated at each follow-up visit and any postural asymmetries, cording, swelling, and/or seromas by visual inspection and palpation were recorded by the therapist. In addition, physical activity, pain, and fatigue were subjectively reported by the patient.

A total of 46 of 196 women with early-stage breast cancer were diagnosed with subclinical lymphedema (defined as $\geq 3 \%$ volume increase of the affected limb from the preoperative measurement and with consideration for the contralateral limb
[6]) at an average 6.9 months (standard deviation [SD] \pm 4.3 ; range, 1-18 months) after surgery. Segmental limb volume data that had been captured by optoelectronic infrared perometry at baseline and at interval follow-up visits before the onset of lymphedema were available for 45 of the 46 women.

Interval arm volume measurements taken before the onset of lymphedema at $10-\mathrm{cm}$ segments along the length of the limb were analyzed retrospectively. The 0 point was marked at the wrist crease, and one segment was defined for each 10-cm increment along the limb. The hand was not included in this analysis. This method yielded 4 limb segments with the 0 point at the wrist: $0-10 \mathrm{~cm}, 10-20 \mathrm{~cm}, 20-30 \mathrm{~cm}$, and $30-40 \mathrm{~cm}$.

With the use of perometer software, circumferential girth was obtained at these segmental markers at each interval measurement before the onset of BCRL. Limb segment volume was calculated on the basis of these circumferences with the use of a truncated cone formula in Microsoft Access [24]. TLV was derived in 2 ways: first, the aggregate sum of the volume of the segments was calculated to yield TLV from 0 to $40 \mathrm{~cm}$. Second, $80 \%$ of the length of the limb as measured from the ulnar styloid process to the acromion process was obtained and perometer software was used to calculate the TLV.

For the purposes of analysis, subjects were included in the lymphedema group upon diagnosis of subclinical BCRL. We used a case-control design, and an age-matched control group of subjects from within the same prospective cohort who had not been diagnosed with lymphedema was selected. Therefore the control group highlights differences in patient and tumor characteristics and in breast cancer treatment between the groups.

All statistical analysis was performed with the use of SPSS version 17 (Chicago, IL). Descriptive statistics were computed for all variables, with significance set at an $\alpha$ of $P \leq .05$. Repeated-measures multivariate analysis of variance [25] was used to compare segmental volumes (0-10, 10-20, 20-30, and $30-40 \mathrm{~cm}$ ) between the lymphedema and control groups (group = between group comparison) at preoperative baseline assessment, at the time of diagnosis of BCRL, and at the time of follow-up after early intervention (time $=$ within comparison) for the affected limb and contralateral (unaffected) limb. Assumptions for the multivariate analysis of variance were met with a normal probability distribution and nonsignificant tests of sphericity.

Linear regression analysis with the use of a least-squares method was performed to determine the strength of the relationship between TLV from $0-40 \mathrm{~cm}$ with segmental volumes from $0-10 \mathrm{~cm}, 10-20 \mathrm{~cm}, 20-30 \mathrm{~cm}$, and $30-40 \mathrm{~cm}$ at the time of diagnosis of BCRL (Figures 1 and 2). The residuals (ie, the deviations from the fitted line to the observed values) were examined to determine the validity of the model. We assessed the strength of the relationship by calculating the coefficient of determination [26]. 

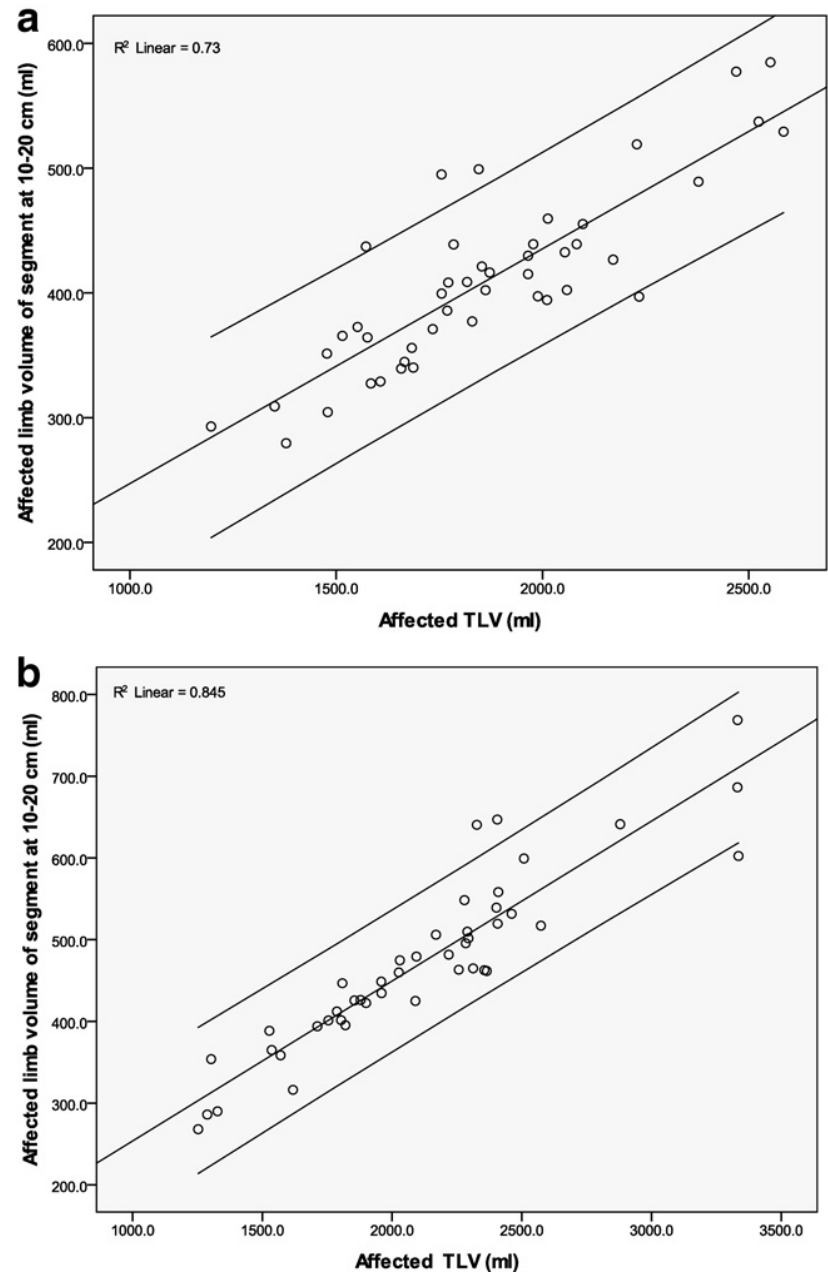

Figure 1. Regression for affected upper limb segmental volume $10-20 \mathrm{~mL}$ at time of diagnosis of breast cancer-related lymphedema of the control group (A) and the lymphedema group (B).

\section{RESULTS}

The lymphedema group consisted of 45 women with earlystage breast cancer with a mean age of 55.8 years (range, 34-82 years; SD \pm 12.1 ). The control group comprised 45 women with a mean age of 55.8 years (range, 33-81 years; $\mathrm{SD} \pm 12.2$ ). The physical characteristics of these groups are shown in Table 1 and differed at baseline only with regard to their affected side from breast cancer $(P=.029)$. Average body mass index (BMI) was not significantly different between groups at baseline; however, when BMI was categorically analyzed (Table 1), BMI classification was significantly different for those classified as overweight $(P=.041)$. BMI was significantly different between groups after early intervention for $\operatorname{BCRL}(P=.043)$, suggesting that the lymphedema group experienced weight gain during the course of treatment for breast cancer. Table 2 shows the breast cancer treatment character- istics of the groups. The groups were significantly different regarding their chemotherapy (taxol, adriamycin, cytoxan [TAC] $)(33.3 \% ; P=.004)$, procedure for breast reconstruction (26.7\%; $P=.001$ ), and occurrence of postoperative axillary web syndrome $(35.6 \% ; P=.026)$, suggesting that these factors may have contributed to the onset of lymphedema.

Statistically significant increases in TLV were noted in the lymphedema group from baseline to the time of diagnosis. Significant increases at the $10-20 \mathrm{~cm}$ and $20-30 \mathrm{~cm}$ segments were noted before the diagnosis of subclinical lymphedema, at diagnosis, and after early intervention compared with the contralateral limb. Table 3 outlines segmental and TLV changes over time for the lymphedema group, noting lower and upper bound confidence intervals.

Linear regression analysis at time of diagnosis of lymphedema for TLV and segment $10-20 \mathrm{~cm}$ yielded a coef-
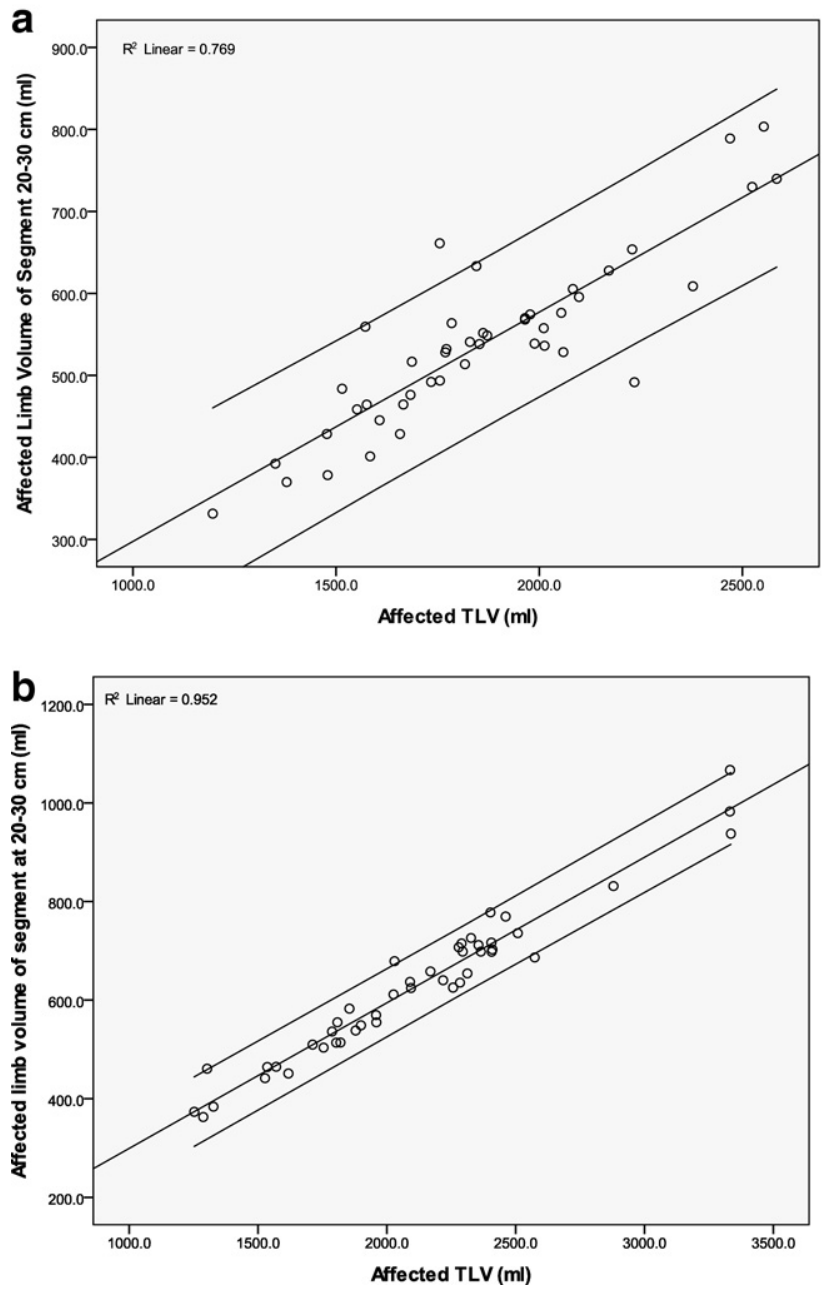

Figure 2. Regression for affected upper limb segmental volume 20-30 mL at time of diagnosis of breast cancer-related lymphedema of control group (A) and lymphedema group (B). 
Table 1. Baseline patient characteristics

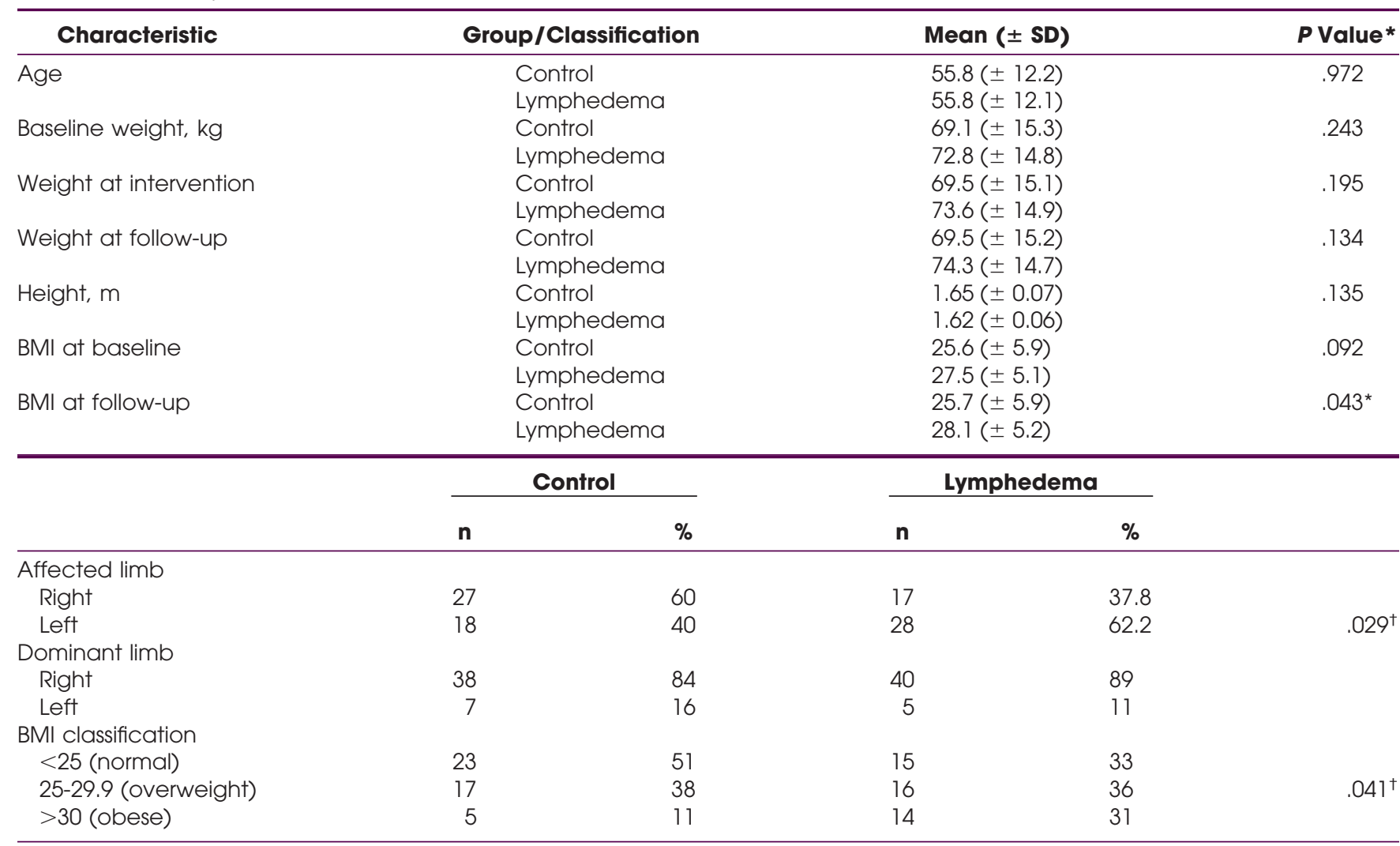

ANOVA = analysis of variance; $\mathrm{BMI}=$ body mass index

$* P<.05$ is significant with all interval data tested by univariate ANOVA at baseline between groups. Weight and BMI were tested by repeated-measures ANOVA (baseline, onset of intervention, and follow-up).

${ }^{\dagger} P<.05$ is significant with nominal data tested by $\chi^{2}$ test.

ficient of determination of $\mathrm{r}^{2}=0.845$ (Figure 1B) for TLV, and segment $20-30 \mathrm{~cm}$ yielded a coefficient of determination of $r^{2}=0.952$ (Figure 2B), suggesting that segmental volume changes at the $10-20 \mathrm{~cm}$ and $20-30 \mathrm{~cm}$ segments may explain the change in TLV.

\section{DISCUSSION}

The concept of segmental drainage is historically referred to in lymphatic anatomy, and these patterns of segmental drainage have been implicated in the development of lymphedema [27]. This concept is further supported by the recent work of Reynolds et al [28], Uren et al [29], and Suami et al [30], whose segmental lymphatic drainage evidence has propelled the concept of sentinel lymph node biopsy in melanoma of the extremities.

Stanton et al [31] highlighted the segmental lymphatic drainage pathways of the upper extremity in BCRL. They demonstrate, with lymphoscintigraphy, that lymphatic drainage pathways of the limb do not flow in an absolute linear, progressive fashion and that segmental variations do indeed exist [20]. These authors note segmental drainage variations in the deeper subfascial compartments of the upper limb, most notably in the muscle compartments and the hand [21,32-34]. Our results demonstrate the clinical presen- tation of disrupted segmental pathways after breast cancer-mitigating therapies.

Stanton et al [20] noted an increase in the lymphatic pressure in the muscle compartments of the upper limb before the onset of lymphedema. They theorize that pressure may be increased in the deep compartments because of the low compliance of muscle tissue. This increase in pressure results in decreased lymph drainage from the superficial tissues into deeper tissues, which is a necessary mechanism in assisting the removal of fluid from the subcutaneous tissue. The epifascial lymphatics then become overloaded and are rendered inefficient in their uptake and drainage of fluid. This scenario gives rise to the theory that an initial clinical presentation of lymph congestion will be distributed in a segmental fashion local to the muscle compartments $[18,31,34]$. Our clinical findings support this notion and suggest that changes at the earliest onset of BCRL would likely occur in the superficial tissue in close proximity to the muscle, primarily the forearm and distal upper arm, as we found.

The segments $10-20 \mathrm{~cm}$ and $20-30 \mathrm{~cm}$ include the proximal forearm and the mid to distal upper arm, commonly referred to 
Table 2. Breast cancer treatment characteristics

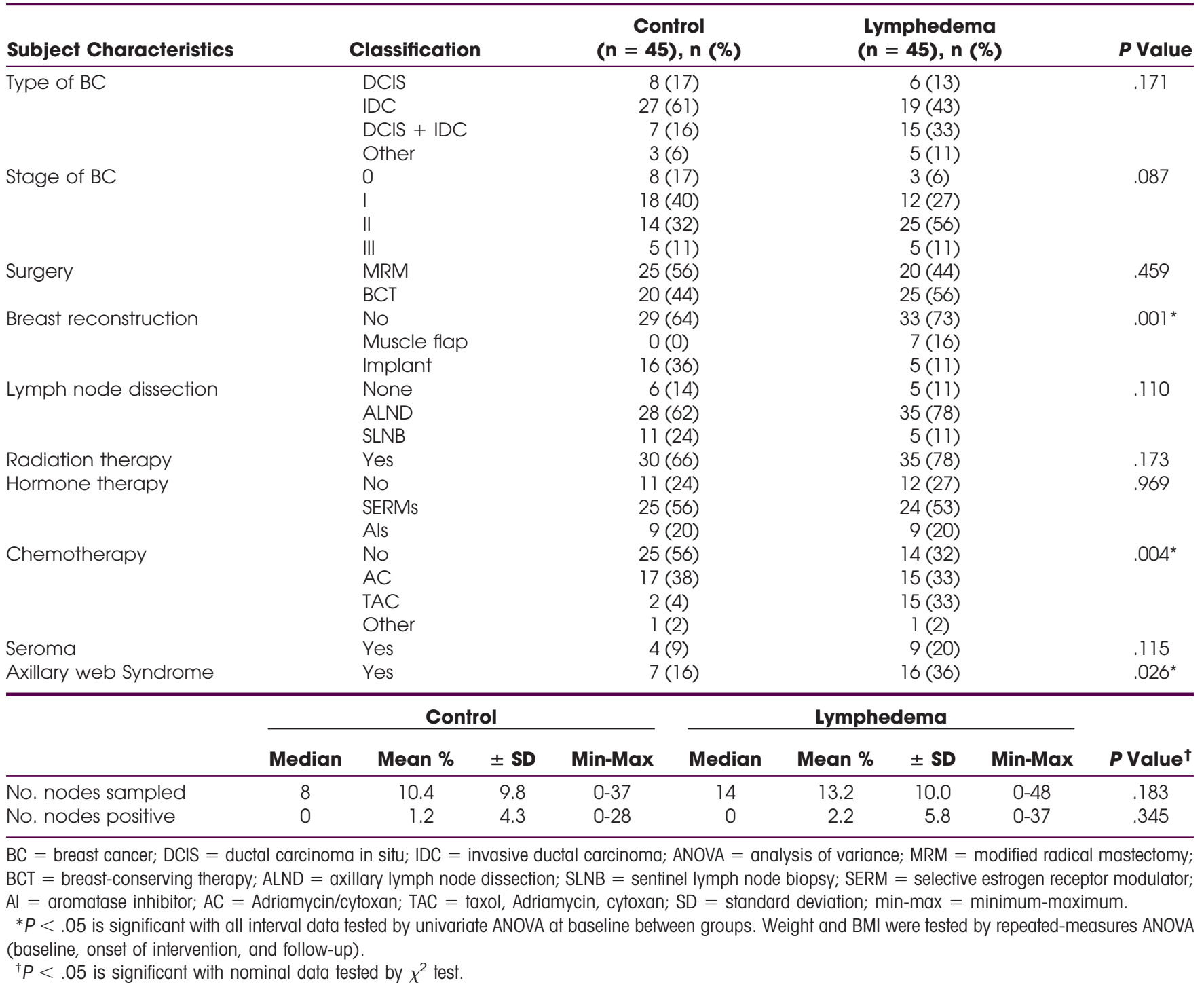

as the pericubital region. Anatomically, this region is an area of muscle tissue bulk that includes the deep forearm compartment. Mellor et al [21] found that in these regions of the arm, fluorescent tracer was transported over a greater epifascial distance of the forearm before draining deep in the swollen arm of women with BCRL. These investigators suggest that microlymphatic changes occur in the swollen arm, namely a local superficial rerouting of lymph drainage in the forearm. Because of this dispersion of fluid through the superficial tissues, we suggest that optimal measurement for lymphedema should be comprehensive; however, segments $10-20 \mathrm{~cm}$ and $20-30 \mathrm{~cm}$ may have the most clinical utility because they are highly significant in their ability to explain a large amount of the variance in TLV and should be explicitly targeted and monitored for meaningful change.

When BCRL is diagnosed and managed at its earliest stages, the condition can be controlled and the adverse effects mini- mized [35]. Early detection of lymphedema relies on a prospective surveillance model and sensitive measurement techniques for accurate assessment and management [35]. The effectiveness of any measurement device to quantify BCRL is constrained by the methodology with which it is used. Preoperative volume measurement enables quantification of normal interlimb variance [36]. Only by assessing our subjects' "normal" preoperative limb differential were we able to use serial postoperative measurements to effectively assess these segmental changes over time and eventually detect subclinical BCRL. Bilateral limb volume assessment should be conducted because weight changes and postsurgical swelling can affect both limbs [37]. Weight changes and postsurgical swelling may account for the volume change we observed in our lymphedema group at the $30-40 \mathrm{~cm}$ segment on the unaffected limb over time (Table 3).

We used optoelectronic perometry for serial volume measurement. Perometry uses infrared light to capture limb con- 
Table 3. Interlimb volume differences and their change over time

\begin{tabular}{|c|c|c|c|c|}
\hline \multirow[b]{2}{*}{ Limb Segment Volume } & \multirow{2}{*}{$\begin{array}{c}\text { Control } \\
\text { Interlimb Volume } \\
\text { Difference, mL }\end{array}$} & \multirow{2}{*}{$\begin{array}{l}\text { Lymphedema } \\
\text { Interlimb Volume } \\
\text { Difference, mL }\end{array}$} & \multicolumn{2}{|c|}{$\begin{array}{l}\text { 95\% Confidence Interval, } \\
\text { Lymphedema Group }\end{array}$} \\
\hline & & & Lower Bound & Upper Bound \\
\hline \multicolumn{5}{|l|}{ Baseline } \\
\hline 0-10 mean (SD) & $7.4( \pm 47.7)$ & $1.4( \pm 58.8)$ & 281.2 & 319.0 \\
\hline $10-20$ & $4.0( \pm 69.3)$ & $5.2( \pm 96.5)$ & 417.0 & 478.1 \\
\hline $20-30$ & $2.7( \pm 99.6)$ & $4.0( \pm 152.0)$ & 545.2 & 637.3 \\
\hline $30-40$ & $0.3( \pm 128.3)$ & $1.6( \pm 206.0)$ & 632.7 & 754.4 \\
\hline Total limb 80\% arm length & $6.7( \pm 278.5)$ & $9.3( \pm 403.3)$ & 1238.7 & 1483.4 \\
\hline \multicolumn{5}{|l|}{ Intervention } \\
\hline $0-10$ & $2.4( \pm 45.8)$ & $17.7( \pm 61.9)$ & 297.7 & 339.2 \\
\hline $10-20(P=.044)^{*}$ & $4.7( \pm 72.3)$ & $28.4( \pm 99.7)(P=.001)^{\dagger}$ & 439.5 & 503.6 \\
\hline $20-30(P<.001)^{*}$ & $0.4( \pm 105.0)$ & $30.9( \pm 149.0)(P<.001)^{\dagger}$ & 582.4 & 637.6 \\
\hline $30-40$ & $1.5( \pm 140.8)$ & $3.6( \pm 209.9)$ & 680.8 & 810.0 \\
\hline Total limb $80 \%$ arm length & $3.5( \pm 283.6)$ & $81.4( \pm 416.6)$ & 1249.0 & 1496.5 \\
\hline \multicolumn{5}{|l|}{ Follow-up } \\
\hline $0-10$ & $1.4( \pm 45.4)$ & $8.6( \pm 59.1)$ & 290.6 & 328.5 \\
\hline $10-20$ & $2.5( \pm 69.8)$ & $9.5( \pm 96.5)$ & 429.1 & 488.4 \\
\hline $20-30(P=.04)^{\star}$ & $5.7( \pm 106.2)$ & $19.1( \pm 142.6)(P=.001)^{\dagger}$ & 570.6 & 657.6 \\
\hline $30-40$ & $12.7( \pm 139.3)$ & $12.4( \pm 184.4)$ & 673.8 & 786.5 \\
\hline Total limb $80 \%$ arm length & $9( \pm 282.5)$ & $36.3( \pm 389.6)$ & 1260.1 & 1495.4 \\
\hline
\end{tabular}

MANOVA = multivariate analysis of variance.

${ }^{*} P=.05$ is significant for change over time as calculated by MANOVA.

${ }^{\dagger} P=.05$ is significant for change between groups as calculated by MANOVA.

tour, and the associated software program calculates TLV and offers interlimb comparison. The perometer, although highly sensitive to limb volume change [23], cannot be used to gauge specific tissue-related changes in the limb. Other measurement tools can reliably measure segmental limb volume, including circumferential measurement and multifrequency bioelectrical impedance $[14,38]$, and when it is used in the context of a prospective model of care, it will enable the earliest diagnosis of lymphedema, which may be subclinical in nature.

Swelling may occur at any point during and after breast cancer treatment. Postoperative acute swelling affects both limbs in the short-term period after surgery, which emphasizes the need for bilateral limb monitoring [37]. The average time to onset of BCRL in our cohort was 6.9 months, suggesting that monitoring during the first year will enable early detection and treatment. Notable changes in deep tissue lymph pressure have been prospectively assessed and are reported to begin at 7 months postoperatively and progress beyond 24 months [20]. This finding contributes to the concept that early subclinical changes possibly occur in the deep compartments and suggests that such segmental changes may provide the earliest presentation of volume change before the onset of BCRL and may require ongoing assessment for a concomitant period. Recent prospective work by Bar Ad et al [39] supports the progressive nature of BCRL, suggesting that patients with mild lymphedema are at an increased risk for progression. Although our analysis only considered the first postoperative year, the importance of continued monitoring beyond the first year after treatment should be considered.
Interestingly, the breast cancer treatment characteristics of our lymphedema group demonstrated significant differences from the control group that were unexpected. Patients in the lymphedema group had more breast reconstruction procedures, tended to have taxane-based chemotherapy regimens, and had higher rates of axillary web syndrome after surgery. This relatively small cohort highlights variables that may be associated with BCRL. The authors of a previous study have demonstrated a possible association but failed to identify the significance of chemotherapy as a definitive risk factor associated with the development of BCRL [40]. Future research should identify and study these variables in larger cohorts to determine whether they are indeed risk factors in the development of early BCRL.

Our work suggests that pericubital upper limb segment volume changes are highly predictive of changes in TLV. The sensitivity and specificity of using only limb volume change to diagnose lymphedema has yet to be analyzed; therefore, a comprehensive evaluation of the patients' reported symptoms, risk factors, and clinical presentation all should be considered in the context of a prospective surveillance model $[11,15]$. This approach may optimize the early diagnosis of lymphedema, perhaps in a subclinical stage.

\section{CLINICAL IMPLICATIONS}

A prospective surveillance approach to identifying lymphedema is an effective method to detect and treat the condition at its earliest onset $[6,8,9]$. The pericubital segments of the limb show 
a significant increase in volume compared with the other limb segments before the onset of subclinical lymphedema. Many measurement tools provide excellent clinical utility for the quantification of limb volume. Only when preoperative assessment of limb volume followed by a prospective interval surveillance model of care is implemented will practicing clinicians be adept in early detection of BCRL. This work suggests that the $10-20 \mathrm{~cm}$ and $20-30 \mathrm{~cm}$ pericubital regions of the limb demonstrate change in volume that is predictive of TLV change, associated with subclinical BCRL. A clinical approach that is simple and targeted to these segments may successfully detect early BCRL when serial measurements are taken in the context of a comprehensive prospective model of care. We suggest that a comprehensive prospective surveillance model of care is optimal for early detection of BCRL.

\section{LIMITATIONS}

This study demonstrates meaningful volumetric data that are shown to be important in detecting early TLV changes. However, this study is a relatively small subset analysis based on a larger cohort trial. Although the trial was prospective in nature, the analysis of limb volume was performed retrospectively and focused on a known diagnosis of lymphedema. Ideally, a prospective trial in which serial segmental measures are conducted with prospective management of meaningful volume changes, preferably with randomization, ultimately will determine the validity of these data for diagnostic purposes.

We focused only on volume changes experienced before the onset of lymphedema. This study contributes only one factor to the overall clinical assessment of a patient. Assessment and diagnosis of early-stage lymphedema requires a comprehensive approach that includes patient-reported symptoms and risk factor assessment [11,40-42].

Our assessment of limb volume excluded the hand. The perometer methodology previously described does not include a measure of the hand. Specific drainage pathways are noted to be dedicated to the hand [17], which further contributes to the premise of segmental lymphatic drainage. These measures were not captured or quantified in our cohort; therefore, it is not known whether hand volume changes would affect these findings.

\section{IMPLICATIONS FOR FUTURE RESEARCH}

Future research would benefit from studying methodology for segmental measurement in the context of a prospective clinical assessment model. Strong predictive factors have been identified in relation to BCRL. In addition, cancer treatment-related risk factors associated with the onset of BCRL are widely reported. A model for risk stratification and clinical prediction rules could be evaluated and extrapolated from these data.

Novel compression therapy trials should consider investigating the implications of compression application at the segments most at risk. Compression gradients that offer greater stiffness in the garment over these tenuous areas should be fabricated and studied in the context of early intervention.

These findings may have implications for early diagnosis of lower extremity lymphedema. Directions in future research could aim to identify a threshold for volume change consistent with lymphedema and assess associated segmental changes in the lower extremity.

\section{CONCLUSION}

Before the onset of BCRL, upper limb segmental limb volume changes occur that are predictive of TLV changes. Segmental assessment of the limb in the absence of swelling may be an important clinical tool to detect early-onset lymphedema. An optimal clinical approach includes prospective surveillance to monitor changes in limb volume that may be predictive of the onset of lymphedema.

\section{ACKNOWLEDGMENTS}

We thank Intramural Research Training Award students Felicia Washington, Sara Tarplin, Violetta Guiterezz, and Wendy Chen from the National Institutes of Health for their contributions to this study.

\section{REFERENCES}

1. Szuba A, Rockson SG. Lymphedema: Classification, diagnosis and therapy. Vasc Med 1998;3:145-156.

2. Chachaj A, Malyszczak K, Pyszel K, et al. Physical and psychological impairments of women with upper limb lymphedema following breast cancer treatment. Psychooncology 2010;19:299-305.

3. Hayes SC, Janda M, Cornish B, Battistutta D, Newman B. Lymphedema after breast cancer: Incidence, risk factors, and effect on upper body function. J Clin Oncol 2008;26:3536-3542.

4. Helms G, Kuhn T, Moser L, Remmel E, Kreienberg R. Shoulder-arm morbidity in patients with sentinel node biopsy and complete axillary dissection - data from a prospective randomised trial. Eur J Surg Oncol 2009;35:696-701.

5. Cinar N, Seckin U, Keskin D, Bodur H, Bozkurt B, Cengiz O. The effectiveness of early rehabilitation in patients with modified radical mastectomy. Cancer Nurs 2008;31:160-165.

6. Stout Gergich NL, Pfalzer LA, McGarvey C, Springer B, Gerber LH, Soballe P. Preoperative assessment enables the early diagnosis and successful treatment of lymphedema. Cancer 2008;112:2809-2819.

7. Todd J SA, Dodwell D, Horgan K, Topping A. A randomised controlled trial of two programmes of shoulder exercise following axillary node dissection for invasive breast cancer. Physiotherapy 2008;94:265-273.

8. Box RC, Reul-Hirche HM, Bullock-Saxton JE, Furnival CM. Physiotherapy after breast cancer surgery: Results of a randomised controlled study to minimise lymphoedema. Breast Cancer ResTreat 2002;75:51-64.

9. Boccardo FM, Ansaldi F, Bellini C, et al. Prospective evaluation of a prevention protocol for lymphedema following surgery for breast cancer. Lymphology 2009;42:1-9.

10. Armer JM. The problem of post-breast cancer lymphedema: Impact and measurement issues. Cancer Invest 2005;23:76-83.

11. Armer JM, Radina ME, Porock D, Culbertson SD. Predicting breast cancer-related lymphedema using self-reported symptoms. Nurs Res 2003:52:370-379. 
12. Godoy JM, Silva SH, Godoy MF. Sensitivity and specificity of combined perimetric and volumetric evaluations in the diagnosis of arm lymphedema. Prague Med Rep 2007;108:243-247.

13. Mayrovitz HN. Assessing local tissue edema in postmastectomy lymphedema. Lymphology 2007;40:87-94.

14. Taylor R, Jayasinghe UW, Koelmeyer L, Ung $O$, Boyages J. Reliability and validity of arm volume measurements for assessment of lymphedema. Phys Ther 2006;86:205-214.

15. Ridner SH, Montgomery LD, Hepworth JT, Stewart BR, Armer JM. Comparison of upper limb volume measurement techniques and arm symptoms between healthy volunteers and individuals with known lymphedema. Lymphology 2007;40:35-46.

16. Ridner SH, Dietrich MS, Deng J, Bonner CM, Kidd N. Bioelectrical impedance for detecting upper limb lymphedema in nonlaboratory settings. Lymphat Res Biol 2009;7:11-15.

17. Stanton AW, Modi S, Mellor RH, et al. A quantitative lymphoscintigraphic evaluation of lymphatic function in the swollen hands of women with lymphoedema following breast cancer treatment. Clin Sci (Lond) 2006;110:553-561.

18. Stanton AW, Mellor RH, Cook GJ, et al. Impairment of lymph drainage in subfascial compartment of forearm in breast cancer-related lymphedema. Lymphat Res Biol 2003;1:121-132.

19. Stanton AW, Svensson WE, Mellor RH, Peters AM, Levick JR, Mortimer PS. Differences in lymph drainage between swollen and non-swollen regions in arms with breast-cancer-related lymphoedema. Clin Sci (Lond) 2001;101:131-140.

20. Stanton AW, Modi S, Mellor RH, LevickJR, Mortimer PS. Recent advances in breast cancer-related lymphedema of the arm: Lymphatic pump failure and predisposing factors. Lymphat Res Biol 2009;7:29-45.

21. Mellor RH, Stanton AW, Azarbod P, Sherman MD, Levick JR, Mortimer PS. Enhanced cutaneous lymphatic network in the forearms of women with postmastectomy oedema. J Vasc Res 2000;37:501-512

22. Modi S, Stanton AW, Mellor RH, Peters AM, Levick JR, Mortimer PS. Regional distribution of epifascial swelling and epifascial lymph drainage rate constants in breast cancer-related lymphedema. Lymphat Res Biol 2005;3:3-15.

23. Stanton AW, Northfield JW, Holroyd B, Mortimer PS, Levick JR. Validation of an optoelectronic limb volumeter (Perometer). Lymphology 1997;30:77-97.

24. Karges JR, Mark BE, Stikeleather SJ, Worrell TW. Concurrent validity of upper-extremity volume estimates: Comparison of calculated volume derived from girth measurements and water displacement volume. Phys Ther 2003;83:134-145.

25. Huberty CJ Morris JD. Multivariate analysis of variance versus multiple univariate analyses. Psychol Bull 1989;105:382-388.

26. Rao CR, Toutenburg H. Linear Models: Least Squares and Alternatives. Springer Series in Statistics. New York, NY: Springer Verlag; 1999.

27. Kubik $S$. The role of the lateral upper arm bundle and the lymphatic watersheds in the formation of collateral pathways in lymphedema. Acta Biol Acad Sci Hung 1980;31:191-200.
28. Reynolds HM, Dunbar PR, Uren RF, Thompson JF, Smith NP. Mapping melanoma lymphoscintigraphy data onto a 3D anatomically based model. Ann Biomed Eng 2007;35:1444-1457.

29. Uren RF, Howman-Giles R, Thompson JF. Patterns of lymphatic drainage from the skin in patients with melanoma. J Nucl Med 2003;44:570-582.

30. Suami H, Taylor GI, Pan WR. The lymphatic territories of the upper limb: Anatomical study and clinical implications. Plast Reconstr Surg 2007;119:1813-1822.

31. Stanton AW, Modi S, Bennett Britton TM, et al. Lymphatic drainage in the muscle and subcutis of the arm after breast cancer treatment. Breast Cancer Res Treat 2009;117:549-557.

32. Pain SJ, Nicholas RS, Barber RW, et al. Quantification of lymphatic function for investigation of lymphedema: Depot clearance and rate of appearance of soluble macromolecules in blood. J Nucl Med 2002;43:318-324.

33. Stanton AW, Holroyd B, Northfield JW, Levick JR, Mortimer PS Forearm blood flow measured by venous occlusion plethysmography in healthy subjects and in women with postmastectomy oedema. Vasc Med 1998;3:3-8.

34. Stanton AW, Levick JR, Mortimer PS. Cutaneous vascular control in the arms of women with postmastectomy oedema. Exp Physiol 1996;81:447-464.

35. Stout Gergich NL, Pfalzer LA, McGarvey C, Springer B, Gerber LH, Soballe P. Preoperative assessment enables the early diagnosis and successful treatment of lymphedema. Cancer 2008;112:2809-2819.

36. Gebruers N, Truijen S, Engelborghs S, De Deyn PP. Volumetric evaluation of upper extremities in 250 healthy persons. Clin Physiol Funct Imaging 2007;27:17-22

37. Haines TP, Sinnamon P. Early arm swelling after breast surgery: Changes on both sides. Breast Cancer Res Treat 2007;101:105-112.

38. Czerniec SA, Ward LC, Lee MJ, Refshauge KM, Beith J, Kilbreath SL. Segmental measurement of breast cancer-related arm lymphoedema using perometry and bioimpedance spectroscopy. Support Care Cancer 2011;19:703-710.

39. Bar Ad V, Cheville A, Solin LJ, Dutta P, Both S, Harris EE. Time course of mild arm lymphedema after breast conservation treatment for earlystage breast cancer. Int J Radiat Oncol Biol Phys 2010;76:85-90.

40. Paskett ED, Naughton MJ, McCoy TP, Case LD, Abbott JM. The epidemiology of arm and hand swelling in premenopausal breast cancer survivors. Cancer Epidemiol Biomarkers Prev 2007;16:775-782.

41. Armer J, Fu MR, Wainstock JM, Zagar E, Jacobs LK. Lymphedema following breast cancer treatment, including sentinel lymph node biopsy. Lymphology 2004;37:73-91.

42. Swenson KK, Nissen MJ, Leach JW, Post-White J. Case-control study to evaluate predictors of lymphedema after breast cancer surgery. Oncol Nurs Forum 2009;36:185-193.

This CME activity is designated for 1.0 AMA PRA Category 1 Credit ${ }^{\mathrm{TM}}$ and can be completed online at me.aapmr.org. Log on to www.me.aapmr.org, go to Lifelong Learning (CME) and select Journal-based CME from the drop down menu. This activity is FREE to AAPMER members and $\$ 25$ for non-members.

\section{CME Question}

Volume changes in which upper limb segment are predictive of changes in the total limb volume in women with early breast cancer prior to the onset of breast cancer-related lymphedema?

a. wrist and hand

b. axillac

c. pericubital

d. proximal arm 